\title{
Response to Selection for Reduced Anthesis-Silking Interval in Four Algerian Maize Populations
}

\author{
Maysoun Benchikh-Lehocine ${ }^{1}$, Pedro Revilla ${ }^{2} \mathbb{D}$, Rosa Ana Malvar ${ }^{2} \mathbb{D}$ and Abderahmane Djemel ${ }^{1, *}$ \\ 1 Ecole Nationale Supérieure Agronomique, Avenue Hassan Badi, El Harrach, 16051 Alger, Algeria; \\ ma_benchikh@yahoo.fr \\ 2 Misión Biológica de Galicia (CSIC), Apartado 28, 36080 Pontevedra, Spain; previlla@mbg.csic.es (P.R.); \\ rmalvar@mbg.csic.es (R.A.M.) \\ * Correspondence: djemeldahmane@yahoo.fr; Tel.: +213-558-41-04-18
}

check for updates

Citation: Benchikh-Lehocine, M.; Revilla, P.; Malvar, R.A.; Djemel, A Response to Selection for Reduced Anthesis-Silking Interval in Four Algerian Maize Populations. Agronomy 2021, 11, 382. https:// doi.org/10.3390/agronomy11020382

Academic Editor: Eleni Tani

Received: 11 January 2021

Accepted: 16 February 2021

Published: 20 February 2021

Publisher's Note: MDPI stays neutral with regard to jurisdictional claims in published maps and institutional affiliations.

Copyright: (c) 2021 by the authors. Licensee MDPI, Basel, Switzerland This article is an open access article distributed under the terms and conditions of the Creative Commons Attribution (CC BY) license (https:// creativecommons.org/licenses/by/ $4.0 /)$.

\begin{abstract}
Drought is the main constraint to maize production in the Mediterranean area. This is the first report of breeding temperate maize populations from the Algerian desert. The objective of this study was to evaluate response to selection for reduced anthesis-silking interval (ASI) in Algerian maize under drought and control conditions. Three cycles of selection for reduced ASI were carried out in four populations under control and drought conditions, and the breeding program was evaluated under both conditions. Selection under drought was more efficient than under control conditions, particularly for the LOM and TAO populations. Selection for low ASI reduced ASI and days per cycle for BTM and IGS, respectively, under drought conditions. Selection for ASI reduced anthesis in BTM, when selected under drought and evaluated under control conditions. Significant yield increase was observed for BTM under optimal conditions. Significant genetic gain for yield was observed for the population LOM under drought. Therefore, the improved Algerian populations BTM and TAO could be a novel source for reducing ASI and for earlier flowering time as a mechanism for avoiding drought. Furthermore, we propose these populations as sources to develop tolerant inbred lines and to find quantitative trait loci for drought tolerance.
\end{abstract}

Keywords: Algerian maize; drought; anthesis silking interval; breeding

\section{Introduction}

Maize (Zea mays L.) is one of the most important crops in the world (http:/ /www.fao. org/faostat/en/\#data/QC (accessed on 1 February 2021)). Because of its relatively short growth duration and its ability to utilize inputs efficiently, maize is potentially capable of producing a large amount of food grain per unit area [1]. Maize has more applications than any other cereal for food, feed, industrial applications, and bio-energy production [2-5]. However, maize is more susceptible to drought particularly under increasing temperature than all other cereals due essentially to the separation of male and female flowers [2,6-8]. Consequently, one of the main consequences of drought stress in maize is the increase in the anthesis-silking interval (ASI) [9]. Maize sensitivity to drought and heat stress may result in yield losses of $15-20 \%$ per year $[4,5,10]$. Such losses is expected to worsen with climate change, particularly in developing countries with an increasing demand for maize [4,11-13]. To meet future demands of the growing world population, the selection of high yielding and drought tolerant maize cultivars are considered the most economically viable solution $[3,14,15]$.

Direct selection for grain yield under drought conditions is often difficult due to the low heritability of grain yield [16] and the risk of occurrence of drought at many growth phases [4]. According to Parajuli et al. [17], the use of secondary traits in breeding programs is one of the best techniques for selecting the best performing genotypes under stress conditions. In this context, Bänziger et al. [9] proposed ASI, leaf senescence, and leaf rolling as selection criteria in drought tolerance breeding programs based on their high heritability 
and positive correlation with performance under stress conditions. Selection under drought stress has been practiced successfully in maize, according to several reports [3,14,15,18-20]. When selection was performed under drought conditions, selected material may perform well under favorable conditions as well; conversely, selected material under favorable conditions may not show good performance when grown under drought stress [18,19]. However, the most widely used strategy is to select for yield under non-stress conditions to increase performance under stress conditions $[3,14,15,20]$.

According to Flint-Garcia et al. [21], the foremost strategy towards the success of such breeding programs is to screen extensive genetic resources to identify plant germplasm with superior drought tolerance. In order to increase the target areas where an improved variety can be grown, commercial breeding focuses on stability across environments around the world, but only 5 to $10 \%$ of maize diversity is used in commercial maize breeding programs because breeders focus on elite materials [22]. This limited diversity is common in breeding programs for various biotic or abiotic stresses, as most of the existing variability has not been adequately evaluated [23]. Therefore, exploiting other favorable sources of drought tolerance alleles under drought conditions is of paramount importance.

To the best of our knowledge, breeding for drought tolerance has not been reported with maize from temperate areas; furthermore, drought tolerant germplasm from temperate deserts have not been used in breeding programs. Recently, various maize accessions have been collected from the Algerian Saharan oases [24]. Saharan maize probably originated from Central American introductions brought by Spanish travelers during the sixteenth century and from subsequent introduction from African neighbor countries [25]. Because of its adaptation over several centuries to extreme conditions [26], a core collection of Saharan maize has been studied in order to be used in breeding programs as an important source of favorable alleles after performing some screening and isolation of elite genotypes. Previous studies revealed that Algerian maize germplasm exhibited high phenotypic and genetic diversity $[24,25,27,28]$ and could provide new alleles for extreme conditions [29-31] and alternative uses such as bio-energy [32]. Djemel et al. [29] reported that the Algerian populations, particularly BTM, TAO, and LOM, maintained their grain yield and yield components under drought conditions, and others such as IGS showed a short ASI compared to checks. Furthermore, we have previously identified heterotic patterns among Algerian, US Corn Belt, and European Flint maize populations which could be used for incorporating Algerian populations into breeding programs involving temperate germplasm [33]. However, Algerian maize needs prebreeding selection for improving yield and other agronomic traits $[24,29,30]$ before incorporation into maize drought breeding programs. In that context, four populations, whose official names are BTM, TAO, LOM, and IGS, previously studied by Djemel et al. [29], were used to carry out three cycles of selection for ASI under both control and drought conditions. To the best of our knowledge, this is the first report of breeding temperate maize populations from the desert. The objective of this study was to evaluate response to selection for reduced ASI in Algerian maize populations.

\section{Materials and Methods}

\subsection{Plant Materials}

A collection of maize germplasm from the oases of the Algerian Sahara [24] was collected in March 2010 and is conserved at the High National School of Agronomy (ENSA) of El Harrach in Algiers (Algeria). Four open-pollinated maize populations (BTM, TAO, IGS, and LOM) were selected for their drought tolerance in previous evaluations to perform three cycles of selection for ASI [29]. The four selected Algerian populations have conic ears with flint yellow kernels and were collected in four different provinces. BMT comes from Taghit (Bechar province, $30^{\circ} 55^{\prime} 00^{\prime \prime} \mathrm{N} 2^{\circ} 02^{\prime} 00^{\prime \prime} \mathrm{O}$ ), TAO from Taourit (Boüra, 36 $23^{\prime} 00^{\prime \prime} \mathrm{N} 3^{\circ} 54^{\prime} 00^{\prime \prime} \mathrm{E}$ ), IGS from Ain Salah (Tamanrasset, $27^{\circ} 11^{\prime} 42^{\prime \prime}$ N $2^{\circ} 29^{\prime} 0^{\prime \prime}$ E), and LOM from Ouled Mahmoude Lamtarfa (Adrar, $\left.28^{\circ} 35^{\prime} 21^{\prime \prime} \mathrm{N} 0^{\circ} 8^{\prime} 59^{\prime \prime} \mathrm{W}\right)$. We used also two checks that were EP17 $\times \mathrm{EP} 42$, a flint single cross, and 
the dent single cross A638 $\times$ EP56, chosen because A638 is a WF9 inbred, previously identified as drought tolerant (A. Ordás, personal communication).

\subsection{Selection Method and Field Trials}

Three cycles of selection were performed under two different conditions: selection under control conditions and under drought stress. Under drought conditions, plants were irrigated except for the period from two weeks before flowering, i.e., about 50 days after sowing, to two weeks after shedding pollen following previous reports $[14,29,34]$. The selection criterion was reduced ASI and vigorous plant appearance. For each of the three cycles of selection, 350 grains were sown in order to have 250 plants and, among them, 25 plant-to-plant crosses were made among the selected plants showing the shortest ASI and vigorous plant appearance. ASI was calculated as the number of days to silking minus the number of days to pollen, and vigor was assessed by using a 1-9 scale, from $1=$ weak appearance to $9=$ very strong appearance. Each plant was used either as male or female only once. The selection intensity was $20 \%$. All crosses per population were harvested and conserved in bulk. From each bulk, a sample of 350 kernels was sown in rows of $3 \mathrm{~m}$, spaced $0.80 \mathrm{~m}$ apart; plants within the row were $0.20 \mathrm{~m}$ apart to perform the next selection cycle. The seeds from all cycles were multiplied in the same season (2015) and location (Algiers) to have homogeneous seed in order to be used in the evaluation trials.

The 30 genotypes evaluated consisted of four populations, the six selection cycles per population ( 3 cycles performed under control and 3 cycles under drought stress), and two checks that were evaluated under both drought and control conditions. Drought stress and control experiments were sown in two adjacent blocks in the same field. The plots were laid out following a $6 \times 5$ lattice design with three replications. Each plot consisted of two rows of $3 \mathrm{~m}$, spaced $0.80 \mathrm{~m}$ apart with $0.20 \mathrm{~m}$ spacing between plants to give a final population density of approximately 60,000 plants ha ${ }^{-1}$. The field trials were sown in the 18th of April, 2016, and at late sowing date (the 4th of May), and in 2017 (sowing date April 19) at Algiers $\left(36^{\circ} 47^{\prime} \mathrm{N}, 2^{\circ} 03^{\prime} \mathrm{E}\right.$, altitude $32 \mathrm{~m}$ a.s.l.), a sub-humid region of the north of Algeria with $690 \mathrm{~mm}$ of annual rainfall. The driest months were April, May, June, and July, with an average of $35.06,37.84,2.54$, and $0.78 \mathrm{~mm}$ of precipitation, respectively, in 2016, and 21.34, 8.38, 4.58, and $0.51 \mathrm{~mm}$ in 2017. During the three evaluation trials, all plots were irrigated immediately after sowing and hand weeding. Drought stress was managed by withdrawing irrigation two weeks before the $50 \%$ anthesis date (when most of the plants were between V8 and V9 stage) until two weeks after flowering. Irrigation was made with $600 \mathrm{~mm}$ of water; however, only $200 \mathrm{~mm}$ was applied for drought treatment. Irrigation was applied every week and, when the trials received water from rainfall, the exact amount was removed from the irrigation supply. All management practices for the control and drought experiments were the same. The following traits were recorded in all evaluation trials: days to anthesis (from planting to $50 \%$ plants shedding pollen), days to silking (from planting to $50 \%$ plants showing silks), plant aspect (1-9 scale: $1=$ weak appearance to $9=$ very strong appearance), plant height (average length in $\mathrm{cm}$ from the soil to the top of the tassel of ten plants per plot), and grain yield (weight of grains per hectare at $140 \mathrm{~g} \mathrm{~kg}^{-1}$ of grain moisture, expressed in $\mathrm{Mg}$ per hectare). ASI was calculated as the difference between days to silking and days to anthesis.

\subsection{Statistical Analyses}

Combined over treatments and individual analyses of variance were performed by using the PROC MIXED procedure of SAS 9.4 [35]. It is a linear mixed model, where the response variable is continuous and symmetrically distributed. Each sowing date $\times$ year combination was considered as one environment. The genotypes and treatments were considered fixed effects, and the genotype $\times$ treatment interaction was also fixed, whereas environment, replicates, and blocks and their interactions were considered random factors.

Means were compared by using the Fisher's protected LSD $(p=0.05)$. Relative yield of each population across selection cycles under drought stress conditions was calculated 
using the following formula: yield performance $=$ yield under drought stress/yield under control conditions. In order to estimate genetic gain over selection cycles, data from each population and their respective cycles under both water treatments were subjected to regression analyses using the PROC MIXED procedure of SAS 9.4 [35]. First-order autoregressive covariance structure was chosen in the within-subject correlation. Differences among populations for all traits were tested by using least square mean adjusted by the value before drought was applied at each sampling time. Coefficients of regression of traits were obtained for each treatment selection condition combination. Within each population, the comparison of the traits regression curves of both control and stress was performed by making orthogonal contrasts between the two treatments' regression parameters.

\section{Results}

The results of the combined analyses of variance across environments showed significant differences between environments for all traits, and between treatments (drought and control conditions) for all traits, except plant aspect, the means of which were 6.45 for control and 6.36 for drought. Environment $\times$ treatment interaction was significant for days to anthesis, days to silking, plant aspect, and grain yield. The genotypic effect was highly significant $(p<0.01)$ for all traits, and the genotype $\times$ treatment interactions were significant for all traits except plant aspect. In addition, the environment $\times$ genotype interactions were only significant for days to anthesis, days to silking, plant aspect, and plant height. The significant genotype $\times$ treatment interactions were generally of rank, indicating that the relative performance of genotypes was different under control conditions and under drought for all traits.

The mean value of plant height decreased along with grain yield under water stress compared to control treatments, and the mean values of days to silking and ASI significantly increased compared to the mean values obtained under control treatment. However, non-significant differences were observed for anthesis and plant aspect under both water regimes (Table 1).

All populations presented a medium maturity between FAO400 and FAO500 and had a relatively short ASI under control conditions. ASI ranged from 1.55 days to 2.77 days under control conditions, while under drought conditions varied from 1.55 to 5.33 . In both selection conditions, the population and their respective selection cycles maintained their plant aspect under both water treatments. Finally, the grain yield of genotypes varied significantly and was drastically reduced under water stress for all populations. Yield under control conditions ranged from $3.13 \mathrm{t} \mathrm{ha}^{-1}$ for A638 $\times$ EP56 to $1.03 \mathrm{tha}^{-1}$ for TAO C0. LOM C1_S $\left(1.03 \mathrm{t} \mathrm{ha}^{-1}\right)$ followed by LOM C3_S $\left(0.99 \mathrm{tha}^{-1}\right)$ had the highest yield under water stress. The yield of LOM C1_S was significantly higher than the yield of the checks (Table 1).

Considering the mean relative yield reduction in the three cycles of selection for each population under drought stress compared to the mean yield of three cycles under control conditions, the selection cycles of LOM had a higher ability to sustain grain yield, with $40.2 \%$ and $30.2 \%$ yield reduction for selection under control and drought selection conditions, respectively; followed by TAO (41.1\% and $38.9 \%)$, BTM ( $51.3 \%$ and $44.8 \%)$, and finally IGS (64.1\% and $64.65 \%)$. In addition, the losses in grain yields due to water stress of the checks used were greater than that of the Algerian populations cited above $(65.2 \%$ for $\mathrm{EP} 17 \times \mathrm{EP} 42$ and $74.8 \%$ for A638 $\times \mathrm{EP} 56$ ).

All populations responded to selection for reduced ASI, regardless of the selection condition, when they were evaluated under drought conditions. The responses of the populations to selection for reduced ASI were not significantly different because regression coefficients did not differ significantly among populations. BMT and IGS evaluated under control conditions when they were selected under drought conditions also showed a significant negative regression coefficient for ASI. Selection for low ASI reduced ASI by 0.26 and 0.23 days per cycle for BTM and IGS, respectively, under drought conditions. In general, the reduction in ASI across all genotypes was more pronounced under drought compared to the control conditions (Table 2). 
Table 1. Means comparison of three mass selection cycles derived from four Algerian maize populations and two mass selection conditions (selection under control and selection under drought conditions) evaluated under control and drought at Algiers in three environments.

\begin{tabular}{|c|c|c|c|c|c|c|c|c|c|c|c|c|}
\hline \multirow[t]{2}{*}{ Cycle } & \multicolumn{2}{|c|}{ Anthesis (Days) } & \multicolumn{2}{|c|}{ Silking (Days) } & \multicolumn{2}{|c|}{ ASI (Days) } & \multicolumn{2}{|c|}{ Plant Aspect } & \multicolumn{2}{|c|}{ Plant Height (cm) } & \multicolumn{2}{|c|}{ Yield (t ha $\left.a^{-1}\right)$} \\
\hline & Control & Drought & Control & Drought & Control & Drought & Control & Drought & Well-Watered & Drought & Control & Drought \\
\hline $\mathrm{BTMCO}^{\mathrm{a}}$ & 72.2 & 69.9 & 69.8 & 74.4 & 2.44 & 4.55 & 6.00 & 6.44 & 165.5 & 123.1 & 1.45 & 0.73 \\
\hline BTM C1_N ${ }^{b}$ & 68.3 & 66.7 & 66.1 & 69.7 & 2.22 & 3.00 & 6.66 & 6.66 & 176.12 & 152.8 & 1.59 & 0.88 \\
\hline BTM C1_S & 67.6 & 66.2 & 65.6 & 68.7 & 2.00 & 2.44 & 6.55 & 6.88 & 175.7 & 157.7 & 1.23 & 0.65 \\
\hline BTM C2_N & 65.6 & 65.2 & 64.0 & 67.7 & 1.55 & 2.44 & 6.77 & 6.33 & 180.0 & 148.5 & 1.65 & 0.80 \\
\hline BTM C2_S & 64.6 & 65.4 & 62.4 & 67.7 & 2.11 & 2.22 & 6.66 & 6.88 & 180.9 & 153.2 & 1.56 & 0.92 \\
\hline BTM C3_N & 64.2 & 65.1 & 61.8 & 67.2 & 2.44 & 2.11 & 6.22 & 6.77 & 176.5 & 149.1 & 1.98 & 0.86 \\
\hline BTM C3_S & 63.0 & 63.6 & 61.4 & 65.7 & 1.55 & 2.11 & 6.55 & 6.33 & 181.2 & 139.3 & 1.38 & 0.73 \\
\hline IGS C0 & 69.8 & 69.8 & 67.0 & 74.6 & 2.77 & 4.77 & 7.00 & 6.66 & 169.7 & 131.5 & 2.17 & 0.82 \\
\hline IGS C1_N & 68.8 & 68.9 & 66.7 & 71.6 & 2.11 & 2.66 & 7.44 & 7.22 & 187.6 & 142.8 & 2.21 & 0.74 \\
\hline IGS C1_S & 67.6 & 66.8 & 65.6 & 69.3 & 2.00 & 2.55 & 7.66 & 7.00 & 195.3 & 166.1 & 2.31 & 0.85 \\
\hline IGS C2_N & 66.4 & 67.3 & 64.2 & 69.8 & 2.22 & 2.44 & 7.88 & 7.33 & 207.8 & 154.2 & 2.10 & 0.88 \\
\hline IGS C2_S & 66.0 & 65.7 & 63.7 & 68.6 & 2.33 & 2.88 & 8.00 & 7.22 & 199.0 & 156.7 & 2.56 & 0.80 \\
\hline IGS C3_N & 66.9 & 65.2 & 64.8 & 68.2 & 2.11 & 3.00 & 7.33 & 7.44 & 209.0 & 154.0 & 2.09 & 0.68 \\
\hline IGS C3_S & 66.0 & 65.0 & 64.1 & 67.4 & 1.88 & 2.44 & 7.33 & 7.00 & 198.9 & 163.7 & 2.09 & 0.81 \\
\hline LOM C0 & 69.9 & 64.1 & 67.8 & 68.3 & 2.11 & 4.22 & 6.88 & 6.66 & 161.6 & 121.0 & 1.14 & 0.80 \\
\hline LOM C1_N & 63.9 & 63.8 & 61.7 & 66.3 & 2.22 & 2.55 & 7.00 & 7.11 & 177.3 & 149.0 & 1.66 & 0.92 \\
\hline LOM C1_S & 63.8 & 63.0 & 61.9 & 65.7 & 1.88 & 2.66 & 6.66 & 6.22 & 172.3 & 138.6 & 1.26 & 1.03 \\
\hline LOM C2_N & 64.3 & 62.9 & 62.3 & 65.2 & 2.00 & 2.33 & 7.33 & 7.22 & 178.4 & 145.8 & 1.45 & 0.97 \\
\hline LOM C2_S & 63.8 & 61.9 & 62.1 & 64.2 & 1.66 & 2.33 & 7.33 & 7.11 & 180.8 & 132.4 & 1.77 & 0.92 \\
\hline LOM C3_N & 62.8 & 60.8 & 60.7 & 62.9 & 2.11 & 2.11 & 6.88 & 7.22 & 175.8 & 143.2 & 1.57 & 0.91 \\
\hline LOM C3_S & 62.0 & 61.0 & 60.3 & 63.0 & 1.66 & 2.00 & 6.44 & 7.22 & 178.5 & 134.4 & 1.18 & 0.99 \\
\hline TAO C0 & 67.4 & 66.8 & 65.7 & 70.7 & 1.77 & 3.88 & 4.22 & 4.22 & 132.3 & 109.4 & 1.03 & 0.56 \\
\hline TAO C1_N & 64.6 & 64.3 & 62.8 & 66.7 & 1.77 & 2.33 & 5.33 & 4.88 & 155.7 & 131.1 & 1.47 & 0.80 \\
\hline TAO C1_S & 62.9 & 62.6 & 61.1 & 64.6 & 1.77 & 2.00 & 5.11 & 4.88 & 161.6 & 130.4 & 1.28 & 0.87 \\
\hline TAO C2_N & 61.9 & 61.4 & 60.2 & 63.7 & 1.66 & 2.22 & 4.88 & 4.00 & 164.6 & 127.2 & 1.39 & 0.74 \\
\hline TAO C2_S & 60.8 & 60.0 & 59.0 & 62.1 & 1.77 & 2.11 & 4.77 & 4.77 & 156.5 & 122.9 & 1.28 & 0.81 \\
\hline TAO C3_N & 60.1 & 59.8 & 58.3 & 61.7 & 1.77 & 1.88 & 4.55 & 4.77 & 146.2 & 122.1 & 1.06 & 0.77 \\
\hline TAOC3_S & 60.0 & 59.0 & 58.4 & 60.6 & 1.55 & 1.55 & 5.22 & 4.55 & 149.7 & 122.2 & 1.13 & 0.58 \\
\hline $\mathrm{EP} 17 \times \mathrm{EP} 42$ & 80.1 & 85.0 & 77.8 & 66.8 & 2.33 & 5.22 & 6.66 & 6.88 & 208.7 & 155.0 & 1.35 & 0.47 \\
\hline A638×EP56 & 60.4 & 61.4 & 57.7 & 90.2 & 2.77 & 5.33 & 6.33 & 7.00 & 203.5 & 151.6 & 3.13 & 0.79 \\
\hline $\mathrm{LSD}^{\mathrm{c}}$ & 3.04 & 3.6 & 3.1 & 3.6 & 0.65 & 0.79 & 0.96 & 0.76 & 17.1 & 14.4 & 0.64 & 0.24 \\
\hline Means & 65.5 & 65.0 & 63.5 & 67.8 & 2.02 & 2.81 & 6.45 & 6.36 & 176.9 & 141.0 & 1.65 & 0.80 \\
\hline
\end{tabular}

${ }^{a}$ C0 indicates the original population (BTM, IGS, LOM, and TAO), and C1, C2, and C3 mean the first, second, and third cycle of selection, respectively; ${ }^{\mathrm{b}} \mathrm{N}$ Mass selected under control condition, $\mathrm{S}$ Mass selected under drought condition; ${ }^{\mathrm{c}}$ least significant difference at $p$ value of 0.05 .

Male and female flowering were significanlty reduced in all populations under both treatments as indirect effect of selection for reducing ASI. For both selection conditions, the coefficients of regression (b) of all flowering related traits were negative in both evaluation regimens, significantly different from zero. The reduction of three days in time to flowering of TAO, when it was selected for reduced ASI and evaluated under drought conditions, was significantly higher than for the other populations.

Concerning plant aspect, the only significant coefficients of regression were for IGS $(b=0.23$ under selection and evaluation under water stress conditions) and LOM ( $b=0.25$, for control selection conditions and evaluated under water stress). For plant height, populations generally responded positively to selection and their values increased under both treatments. In the selection under drought, the coefficients of regression were positive and only significant for IGS under control conditions and for most populations except for TAO under water stress. Selection for reduced ASI under control condition had a stronger indirect response for plant height under control than under water stress conditions. The regression analysis was significant for BTM, IGS, and LOM under control and only for IGS under water stress conditions. Finally, grain yield, which is the most important trait to improve in Algerian maize populations, did not show a positive indirect response generally. The regression coefficient was only significant and positive for BTM $\left(b=0.17 \mathrm{t} \mathrm{ha}^{-1}\right.$ per cycle) under control conditions when the selection was carried out under drought conditions. 


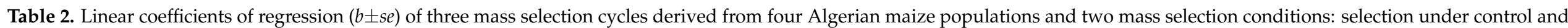
selection under drought) evaluated under control and drought at Algiers in three environments.

\begin{tabular}{|c|c|c|c|c|c|c|c|c|}
\hline \multirow{2}{*}{ Traits } & \multicolumn{4}{|c|}{ Selection under Control Conditions } & \multicolumn{4}{|c|}{ Selection under Drought Conditions } \\
\hline & BTM & IGS & LOM & TAO & BTM & IGS & LOM & TAO \\
\hline \multicolumn{9}{|l|}{ Control evaluation } \\
\hline Anthesis (days) & $-2.60^{* *} \pm 0.39 a^{a}$ & $-1.00 * * \pm 0.39 b$ & $-2.12^{* *} \pm 0.39 a$ & $-2.29^{* *} \pm 0.39 \mathrm{ab}$ & $-3.02 * * \pm 0.38 a$ & $-1.29^{* *} \pm 0.38 b$ & $-2.38^{* *} \pm 0.38 \mathrm{a}$ & $-2.29^{* *} \pm 0.38 \mathrm{ab}$ \\
\hline Silking (days) & $-0.38^{* *} \pm 0.38 b$ & $-0.81 * \pm 0.38 b$ & $-2.11^{* *} \pm 0.38 \mathrm{a}$ & $-2.28^{* *} \pm 0.38 \mathrm{a}$ & $-2.76^{* *} \pm 0.38 \mathrm{a}$ & $-1.05^{* *} \pm 0.37 \mathrm{~b}$ & $-2.22 * * \pm 0.37 a$ & $-2.23^{* *} \pm 0.38 \mathrm{a}$ \\
\hline ASI (days) & $-0.05 \pm 0.11 \mathrm{a}$ & $-0.19 \pm 0.11 a$ & $-0.01 \pm 0.11 \mathrm{a}$ & $-0.01 \pm 0.11 \mathrm{a}$ & $-0.26 * \pm 0.11 \mathrm{a}$ & $-0.23 * \pm 0.11 \mathrm{a}$ & $-0.15 \pm 0.11 \mathrm{a}$ & $-0.06 \pm 0.11 \mathrm{a}$ \\
\hline Plant Aspect & $0.00 \pm 0.16 a$ & $0.15 \pm 0.15 a$ & $0.004 \pm 0.15 \mathrm{a}$ & $0.06 \pm 0.16 \mathrm{a}$ & $0.17 \pm 0.15 \mathrm{a}$ & $0.13 \pm 0.15 a$ & $-0.08 \pm 0.15 a$ & $0.23 \pm 0.15 a$ \\
\hline Plant height $(\mathrm{cm})$ & $2.71 \pm 2.30 \mathrm{a}$ & $13.62^{* *} \pm 2.29 b$ & $3.91 \pm 2.29 \mathrm{a}$ & $4.48 \pm 2.30 \mathrm{a}$ & $4.85^{*} \pm 2.28 \mathrm{a}$ & $9.10^{* *} \pm 2.27 \mathrm{a}$ & $5.52 * \pm 2.27 a$ & $4.26 \pm 2.29 a$ \\
\hline Yield $\left(\mathrm{Mg}^{\circ} \mathrm{ha}^{-1}\right)$ & $0.17^{*} \pm 0.08 \mathrm{a}$ & $-0.04 \pm 0.08 b$ & $0.10 \pm 0.08 \mathrm{ab}$ & $0.01 \pm 0.07 \mathrm{ab}$ & $0.01 \pm 0.08 \mathrm{a}$ & $0.00 \pm 0.08 \mathrm{a}$ & $0.04 \pm 0.07 \mathrm{a}$ & $0.03 \pm 0.07 a$ \\
\hline \multicolumn{9}{|l|}{ Drought evaluation } \\
\hline Anthesis (days) & $-1.58^{* *} \pm 0.33 \mathrm{ab}$ & $-1.60^{* *} \pm 0.33 \mathrm{ab}$ & $-1.09^{* *} \pm 0.33 a$ & $-2.44^{* *} \pm 0.32 b$ & $-1.96^{* *} \pm 0.32 \mathrm{ab}$ & $-1.51^{* *} \pm 0.32 \mathrm{ab}$ & $-1.03^{* *} \pm 0.32 b$ & $-2.63^{* *} \pm 0.32 c$ \\
\hline Silking (days) & $-2.35^{* *} \pm 0.35 \mathrm{ab}$ & $-2.19^{* *} \pm 0.35 \mathrm{ab}$ & $-1.78^{* *} \pm 0.35 \mathrm{a}$ & $-3.06^{* *} \pm 0.34 \mathrm{~b}$ & $-2.74^{* *} \pm 0.34 \mathrm{ab}$ & $-2.21^{* *} \pm 0.34 \mathrm{ab}$ & $-1.73^{* *} \pm 0.34 b$ & $-3.37^{* *} \pm 0.34 c$ \\
\hline ASI (days) & $-0.79 * * \pm 0.12 \mathrm{a}$ & $-0.55^{* *} \pm 0.12 \mathrm{a}$ & $-0.68^{* *} \pm 0.12 \mathrm{a}$ & $-0.62^{* *} \pm 0.12 \mathrm{a}$ & $-0.75^{* *} \pm 0.12 \mathrm{a}$ & $-0.66^{* *} \pm 0.12 a$ & $-0.71^{* *} \pm 0.12 \mathrm{a}$ & $-0.72^{* *} \pm 0.12 \mathrm{a}$ \\
\hline Plant Aspect & $0.07 \pm 0.12 \mathrm{a}$ & $0.23 * \pm 0.12 a$ & $0.20 \pm 0.12 \mathrm{a}$ & $0.07 \pm 0.12 \mathrm{a}$ & $-0.01 \pm 0.12 \mathrm{a}$ & $0.15 \pm 0.12 \mathrm{a}$ & $0.25^{*} \pm 0.112 \mathrm{a}$ & $0.08 \pm 0.12 \mathrm{a}$ \\
\hline Plant height (cm) & $7.98^{* *} \pm 2.44 a$ & $9.77^{* *} \pm 2.46 a$ & $6.77^{* *} \pm 2.47 a$ & $4.40 \pm 2.49 a$ & $4.75 \pm 2.53 \mathrm{ab}$ & $11.10^{* *} \pm 2.52 \mathrm{a}$ & $2.63 \pm 2.52 b$ & $3.36 \pm 2.51 b$ \\
\hline Yield $\left({\left.\mathrm{Mg} . h a^{-1}\right)}^{\prime}\right.$ & $0.03 \pm 0.04 a$ & $-0.02 \pm 0.04 a$ & $0.04 \pm 0.04 \mathrm{a}$ & $0.06 \pm 0.04 a$ & $0.02 \pm 0.04 \mathrm{a}$ & $-0.01 \pm 0.04 a$ & $0.06 \pm 0.04 b$ & $-0.01 \pm 0.04 a$ \\
\hline
\end{tabular}

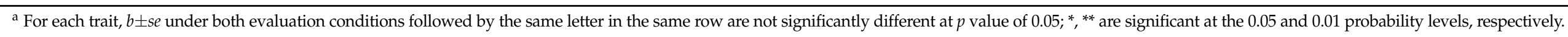




\section{Discussion}

The differences observed for most agronomic traits could be attributed to environmental effects or genetic diversity of the materials evaluated. According to Djemel et al. [24,29], Algerian maize presents a high degree of genetic diversity. Our results agree with these studies because significant differences were observed between populations and their respective cycles of selection. Significant genotype $\times$ treatment interactions were found and generally they were of rank, as the relative value for most traits was not consistent among control and drought treatments. Therefore, breeding and selection of Algerian maize populations for improved yield stability has to be carried out under the specific target water managed environment [14]. Algerian germplasm is an important potential source of drought tolerance for maize breeding because it has been largely adapted to harsh environments and can introduce new allelic diversity into breeding programs $[24,29,30]$. However, these new materials need to be selected to maximize their agronomic traits, especially yield [24,29].

Means were significantly reduced under drought conditions for plant height along with grain yield under drought compared to control conditions as previously reported [36]. Days to silking and ASI significantly increased under drought compared to the mean values obtained under control conditions (Table 1). However, non-significant differences were observed for anthesis under both water regimes (Table 1). Our results were in accordance with those obtained by Welcker et al. [7]. These authors reported that days to anthesis was not affected by drought stress and ASI was associated with days to silking. This mechanism is interpreted as a delay in the growth and development of ovules and silks subjected to drought conditions [7]. According to Edmeades et al. [37], genotypes selected based on a short ASI under drought generally use less carbohydrate in the growth of tassels, leaving a greater proportion of nutrients for the growth of the ear. Many maize breeding programs have focused on reducing the effects of drought at floral development and flowering. Moreover, Herrero and Johnson [38] reported that silk elongation is strongly inhibited by plant water deficits, and this inhibition can lead to severe losses in grain yield.

In the current study, ASI was used as main selection criterion with the goal of indirectly improving the yield of four Algerian maize populations. All populations responded to selection, and the regression coefficients were not significantly different between populations or between selection conditions, although the response was significant only when the evaluation was made under drought conditions. As expected, ASI was highest under stress conditions. According to Bolaños and Edmeades [14], the heritability of ASI remains stable and/or increased as the severity of the drought increased; therefore, the choice of the ideal environment is critical for increasing the genetic gain. Ribaut et al. [39] also reported that the selection environment should mirror the target environment. Monneveux et al. [15] evaluated direct responses to recurrent selection for drought tolerance in two CIMMYT (International Maize and Wheat Improvement Center) maize populations DTP1 and DTP2. These authors revealed that the recurrent selection resulted in a significant decrease in ASI; however, the changes under optimal conditions were smaller in magnitude compared to stress conditions. Algerian maize populations responded positively to the selection criteria but in our study, the gain obtained was independent of the selection environment. Our results did not show an advantage of selecting for lower ASI breeding program under drought conditions, which disagrees with Arboleda-Rivera and Compton [18] who postulated that selection is more successful when performed under drought stress, and with Monneveux et al. [15] who confirmed the effectiveness of recurrent selection under drought as a means of improving tropical maize source populations for performance under drought stress.

Indirect responses in unselected traits, such as flowering time or yield, were also observed. Selection resulted in significant decreases in anthesis and silking under both selection conditions and under both water treatments. As previously reported, ASI is essentially linked to the silking date which is largely affected by stress [7]. Ordás et al. [40] evaluated 18 cycles of recurrent mass selection using silking as a main selection criterion in two maize populations. These authors reported a response of -1.01 days per cycle. In 
addition, Hallauer et al. [22] revealed decreases in days to silking that varied from 1.1 to 2.3 days per breeding cycle. Furthermore, a reduction of 0.39 days per cycle in the BS17 population was observed after five cycles of selection for earliness by Samayoa et al. [41]. All these breeding programs were performed under control conditions. In our study, the change in silking ranged from -0.38 to -2.28 days per cycle under optimal conditions, and from -1.78 to -3.06 days per cycle under drought when selection was carried out under control conditions, and the variation was from -1.05 to -2.76 and from -1.73 to -3.37 under control and drought stress, respectively, when selection was made under drought. In general, our values were higher than those published previously, particularly when evaluation was performed under drought conditions. The positive response to selection using ASI under water stress and the positive indirect responses to earlier female flowering were evidence of the high genetic variability of Algerian maize populations and their adaptation to drought conditions. Early flowering and reduced ASI are mechanisms to escape drought conditions, according to Djemel et al. [29], who concluded that Algerian germplasm has developed diverse adaptation mechanisms to face drought conditions. Ordás et al. [40] confirmed that the continuous response to selection suggests that many loci, each with small effect, are involved. Our results show that Algerian maize populations from the Saharan oases can be employed to develop early inbred lines with short ASI and to find quantitative trait loci for drought avoidance which, according to Hawtin et al. [42], may be found in extreme environments.

Plant aspect was used as criteria to improve the general performance of the populations under drought. Differences among genotypes were not significant for plant aspect under control and drought stress over combined selection conditions (6.45 vs. $6.36 \mathrm{vi}-$ sual score, respectively). The coefficients of regression were positive and significant for IGS ( $b=0.23$, selected under control condition and evaluated under water stress) and LOM ( $b=0.25$, selected and evaluated under water stress) but they did not differ significantly from the regression coefficients of other populations evaluated under drought. As observed for ASI, the values of plant aspect were higher under stress conditions. Ribaut et al. [43] found significant associations between grain yield and leaf related traits. Badu-Apraku et al. [44] also used plant aspect under drought stress to select drought tolerant maize genotypes. Furthermore, Welcker et al. [7] suggested that growth of leaves and silks, and their degrees of maintenance under drought conditions, were genetically linked. Our results show that selection programs based on ASI, and including plant aspect as secondary selection criterion, under both drought or control conditions could be effective when evaluated under drought conditions.

Alhough the relationship between plant height and yield is not consistent, low plant height in dwarf maize has been proposed as a mechanism of adaptation to drought conditions [45]. Low plant height was also associated with increased yield under drought conditions [39]. Monneveux et al. [15] found that plant height was unaffected by selection under drought stress. Fischer et al. [19] reported that yield was positively correlated with plant height under both mild and severe drought stress. However, Ordás et al. [40] reported a response of $-3.7 \mathrm{~cm} /$ cycle in plant height change after 18 cycles of selection for early silking in maize. These authors affirmed that reduced plant height with selection could be caused by selecting early flowering or by inbreeding ( $0.8 \%$ per cycle). In our study, the inbreeding coefficient $(1 / 2 \mathrm{~N}$, were $\mathrm{N}=50$, a population size used in each cycle of selection) was 1\%. According to Ordás et al. [40], this coefficient was lower and should not contribute to decreased plant height. The increase in plant height in our experiment should be engendered by selection criteria using plant aspect. According to Rocheford [46] (2009), unintentional selection of more vigorous plants may contribute to the maintenance of heterozygosity.

This study aimed at improve Algerian maize production under drought for potential use in further maize breeding. However, the increase in grain yield was only significant for BTM selected under drought conditions when evaluated under control conditions ( $0.17 \mathrm{t} \mathrm{h}^{-1}$ per cycle). No changes were observed in the other populations. According 
to Monneveux et al. [15], average yield gains were $0.16 \mathrm{t} \mathrm{ha}^{-1}$ per cycle and $0.08 \mathrm{t} \mathrm{ha}^{-1}$ per cycle in DTP1 and DTP2, respectively, using recurrent selection under drought. In the landrace "Tuxpeño Sequía", yield gain varied from 0.09 to $0.13 \mathrm{t} \mathrm{ha}^{-1}$ per cycle after eight cycles of selection and was similar under optimal and stressed conditions [36]. At CIMMYT, population yield improvement by selection at flowering stage has been accomplished, and the grain yield ranged from $0.08 \mathrm{tha}^{-1}$ to $0.26 \mathrm{t} \mathrm{ha}^{-1}$ per selection cycle [36]. Despite the non-significant regression, LOM responded positively to selection under water stress when evaluated under water stress, with LOM C1_S (1.03 $\left.\mathrm{t} \mathrm{ha}^{-1}\right)$ being the highest yielding cycle followed by LOM C3_S $\left(0.99 \mathrm{t} \mathrm{ha}^{-1}\right)$, where C1_S and C3_S stand for the first and the third cycles of selection under drought conditions, respectively. Furthermore, yield under water stress was the highest $(30.16 \%$ of yield loss) for LOM with good plant aspect under drought $(b=0.25$ gain per cycle). Because the low heritability of grain yield under drought stress conditions [16], genetic gain progress is hard to achieve-for this reason LOM is a good candidate for breeding maize under drought conditions. Djemel et al. [29] also reported that Algerian populations had large variability for most traits, and the populations BTM and LOM out yielded most checks under drought. In the previous study, the relative yield performance (ratio yield under drought/yield under control conditions) was 0.659, 0.653, and 0.532 for BTM, TAO, and LOM, respectively. These populations were able to maintain their yield components (grain weight, ear length, number of kernel rows, and ears per plant) and leaf area under drought; furthermore, they presented reduced leaf rolling. TAO and BTM presented the highest relative water content and LOM had the highest proline content [29].

\section{Conclusions}

Algerian maize responded positively to selection because the coefficients of regression for ASI were negative and significant for all populations evaluated under drought conditions, and for BTM and IGS when selected under drought and evaluated under control conditions. Furthermore, selection performed under water stress was similar to selection under control conditions for ASI, indicating that reducing ASI under control conditions could have favorable response also under drought stress. Significant yield gain $\left(0.17 \mathrm{t} \mathrm{ha}^{-1}\right.$ per cycle) was observed in BTM when it was selected and evaluated under control conditions. Furthermore, data from the present report suggest that selection for reduced ASI under drought conditions may result in an increase in yield ( $\mathrm{LOM}=0.06 \mathrm{t} \mathrm{ha}^{-1}$ per cycle) under drought. The Algerian maize population LOM could be a source of drought tolerance, based on the variation of yield under drought conditions, while the BTM and TAO populations could be considered a novel source for reduced ASI and earliness under drought.

As this local germplasm has low yield, a convenient strategy could consist of carrying out intrapopulation breeding programs for improving yield; an alternative strategy is making crosses between populations, selected as potential sources of drought tolerance, and modern inbred lines that provide favorable alleles for yield. Additionally, a more practical approach consists of releasing inbred lines from those populations under drought conditions. Indeed, several modern inbred lines have some drought tolerance and could be used for subsequent improvement of drought tolerance, but they have narrow genetic diversity; furthermore, local populations adapted to extremely arid environments should contain alleles that are not available in current breeding programs, especially in commercial temperate maize breeding programs. Finally, precise evaluations can be carried out in phenotypic platforms.

Author Contributions: M.B.-L., data recording and draft preparation; P.R., manuscript correction and final redaction; R.A.M., data analyses; A.D., conceptualization, materials, experimental design, data recording and analyses, draft preparation and redaction. All authors have read and agreed to the published version of the manuscript. 
Funding: This research was funded by École Nationale Supérieure Agronomique d'Alger, and the Spanish Ministerio de Innovación y Universidades (MCIU), the Agencia Estatal de Investigación (AEI) and the European Fund for Regional Development (FEDER), UE (project code PID2019-108127RB-I00).

Institutional Review Board Statement: Not applicable.

Informed Consent Statement: Not applicable.

Data Availability Statement: Data available from authors upor request.

Conflicts of Interest: The authors declare no conflict of interest.

\section{References}

1. Ajani, O.T.; Oluwaranti, A.; Awoniyi, A.I. Assessment of water-use efficiency of drought tolerant maize (Zea mays L.) varieties in a rainforest location. J. Agric. Ecol. Res. Int. 2016, 8, 1-10. [CrossRef]

2. Huang, R.; Birch, C.J.; George, D.L. Water use efficiency in maize production-the challenge and improvement strategies. Water to Gold. In Proceedings of the 6th triennial Conference, Griffith, NSW, Australia, 21-23 February 2006; Maize Association of Australia: Darlington Point, NSW, Australia, 2006.

3. Anami, S.; Block, M.D.; Machuka, J.; Lijsebettens, M.V. Molecular improvement of tropical maize for drought stress tolerance in Sub-Saharan Africa. Crit. Rev. Plant. Sci. 2009, 28, 16-35. [CrossRef]

4. Chen, J.P.; Xu, W.W.; Velten, J.; Xin, Z.G.; Stout, J. Characterization of maize inbred lines for drought and heat tolerance. J. Soil Water Conserv. 2012, 67, 354-364. [CrossRef]

5. Khan, N.H.; Ahsan, M.; Naveed, M.; Hafeez, A.; Sadaqat, H.A.; Javed, I. Genetics of drought tolerance at seedling and maturity stages in Zea mays L. Span. J. Agric. Res. 2016, 14, 705-716. [CrossRef]

6. Bänziger, M.; Araus, J.L. Recent advances in breeding maize for drought and salinity stress tolerance. In Advances in Molecular Breeding toward Drought and Salt Tolerant Crops; Jenks, M.A., Hasegawa, P.M., Jain, S.M., Eds.; Springer: Dordrecht, The Netherlands, 2007; pp. 587-601.

7. Welcker, C.; Boussuge, B.; Bencivenni, C.; Ribaut, J.M.; Tardieu, F. Are source and sink strengths genetically linked in maize plants subjected to water deficit? A QTL study of the responses of leaf growth and of anthesis-silking interval to water deficit. J. Exp. Bot. 2007, 58, 339-349. [CrossRef]

8. Vinodhana, N.K.; Ganesan, K.N. Analysis of physico-genetic traits for drought tolerance in maize (Zea mays L.). Int. J. Curr. Microbiol. App. Sci. 2017, 6, 4568-4575. [CrossRef]

9. Bänziger, M.; Edmeades, G.O.; Beck, D.; Bellon, M. Breeding for Drought and Nitrogen Stress Tolerance in Maize. From Theory to Practice; D.F. CIMMYT: Mexico, Mexico, 2000.

10. Ziyomo, C.; Bernardo, R. Drought tolerance in maize: Indirect selection through secondary traits versus genome wide selection. Crop. Sci. 2013, 53, 1269-1275. [CrossRef]

11. Betrán, F.J.; Beck, D.; Bänziger, M.; Edmeades, G.O. Genetic analysis of inbred and hybrid grain yield under stress and non-stress environments in tropical maize. Crop. Sci. 2003, 43, 807-817. [CrossRef]

12. Campos, H.; Cooper, M.; Edmeades, G.O.; Löffler, C.; Schussler, J.R.; Ibañez, M. Changes in drought tolerance in maize associated with fifty years of breeding for yield in the U.S. Corn Belt. Maydica 2006, 51, 369-381.

13. Witt, S.; Galicia, L.; Lisec, J.; Cairns, J.; Tiessen, A.; Araus, J.L.; Palacios-Rojasand, N.; Fernie, A.R.R. Metabolic and phenotypic responses of greenhouse-grown maize hybrids to experimentally controlled drought stress. Mol. Plant. 2012, 5, 401-417. [CrossRef] [PubMed]

14. Bolaños, J.; Edmeades, G.O. The importance of the anthesis-silking interval in breeding for drought tolerance in tropical maize. Field Crops Res. 1996, 48, 65-80. [CrossRef]

15. Monneveux, P.; Sanchez, C.; Beck, D.; Edmeades, G.O. Drought tolerance improvement in tropical maize source populations: Evidence of progress. Crop. Sci. 2006, 46, 180-191. [CrossRef]

16. Edmeades, G.O.; Bolaños, J.; Chapman, S.C.; Lafitte, H.R.; Bänziger, M. Selection improves drought tolerance in tropical maize populations: I. Gains in biomass, grain yield, and harvest index. Crop. Sci. 1999, 39, 1306-1315. [CrossRef]

17. Parajuli, S.; Ojha, B.R.; Ferrara, G.O. Quantification of secondary traits for drought and low nitrogen stress tolerance in inbreds and hybrids of maize (Zea mays L.). J. Plant. Genet. Breed. 2018, 2, 106-118.

18. Arboleda-Rivera, F.; Compton, W.A. Differential response of maize (Zea mays L.) to mass selection in diverse selection environments. Theor. Appl. Genet. 1974, 44, 77-81. [CrossRef]

19. Fischer, K.S.; Edmeades, G.O.; Johnson, E.C. Selection for the improvement of maize yield under moisture-deficits. Field Crops Res. 1989, 22, 227-243. [CrossRef]

20. Maazou, A.R.S.; Tu, J.; Qiu, J.; Liu, Z. Breeding for Drought Tolerance in Maize (Zea mays L.). Am. J. Plant. Sci. 2016, 7, 1858-1870. [CrossRef]

21. Flint-Garcia, S.A.; Thuillet, A.C.; Yu, J.; Pressoir, G.; Romero, S.M.; Mitchell, S.E.; Debley, J.; Kresovich, S.; Major, M.M.; Buckler, E.S. Maize association population: A high resolution platform for quantitative trait locus dissection. Plant J. 2005, 44, 1054-1064. [CrossRef] [PubMed]

22. Hallauer, A.R.; Carena, M.J.; Miranda, J.B. Quantitative Genetics in Maize Breeding; Springer: New York, NY, USA, 2010. 
23. Romay, M.C.; Butrón, A.; Ordás, A.; Revilla, P.; Ordás, B. Effect of recurrent selection on the genetic structure of two broad-based Spanish maize populations. Crop. Sci. 2012, 52, 1493-1502. [CrossRef]

24. Djemel, A.; Revilla, P.; Hanifi-Mekliche, L.; Malvar, R.A.; Álvarez, A.; Khelifi, L. Maize (Zea mays L.) from the Saharan oasis: Adaptation to temperate areas and agronomic performance. Genet. Resour. Crop. Evol. 2012, 59, 1493-1504. [CrossRef]

25. Aci, M.M.; Revilla, P.; Morsli, A.; Djemel, A.; Belalia, N.; Kadri, Y.; Khelifi-Saloui, M.; Ordás, B.; Khelifi, L. Genetic diversity in Algerian maize (Zea mays L.) landraces using SSR markers. Maydica 2013, 58, 304-310.

26. Laumont, P.; Laby, H. Le maïs et sa culture en Algérie. Governement Général Algérie, Doc. et Rens. Agricoles. Bull. $n^{\circ} 155$ et broch. 47 p., Alger. 1950.

27. Aci, M.M.; Lupini, A.; Mauceri, A.; Morsli, A.; Khelifi, L.; Sunseri, F. Genetic variation and structure of maize populations from Saoura and Gourara oasis in Algerian Sahara. BMC Genet. 2018, 19, 1-10. [CrossRef]

28. Belalia, N.; Lupini, A.; Djemel, A.; Morsli, A.; Mauceri, A.; Lotti, C.; Khelifi-Slaoui, M.; Khelifi, L.; Sunseri, F. Analysis of genetic diversity and population structure in Saharan maize (Zea mays L.) populations using phenotypic traits and SSR markers. Genet. Resour. Crop. Evol. 2019, 66, 243-257. [CrossRef]

29. Djemel, A.; Cherchali, F.Z.; Benchikh-Le-Hocine, M.; Malvar, R.A.; Revilla, P. Assessment of drought tolerance among Algerian maize populations from oases of the Saharan. Euphytica 2018, 214, 1-11. [CrossRef]

30. Djemel, A.; Álvarez-Iglesias, L.; Santiago, R.; Malvar, R.A.; Pedrol, N.; Revilla, P. Algerian maize populations from the Sahara Desert as potential sources of drought tolerance. Acta Physiol. Plant. 2019, 41, 12. [CrossRef]

31. Maafi, O.; Revilla, P.; Álvarez-Iglesias, L.; Malvar, R.A.; Djemel, A. Adaptation assessment of drought tolerant maize populations from the Sahara in both shores of the Mediterranean Sea. Euphytica 2021. (under revision).

32. López-Malvar, A.; Djemel, A.; Santiago, R.; Revilla, P. Assessment of Algerian maize populations for saccharification and nutritive value. Agronomy 2020, 10, 646. [CrossRef]

33. Cherchali, F.Z.; Ordás, B.; Revilla, P.; Pedrol, N.; Djemel, A. Heterotic patterns among Algerian, US Corn Belt, and European Flint maize populations under the Mediterranean conditions of North Africa. Crop. Sci. 2018, 58, 1-11. [CrossRef]

34. Gouesnard, B.; Zanetto, A.; Welcker, C. Identification of adaptation traits to drought in collections of maize landraces from southern Europe and temperate regions. Euphytica 2016, 209, 565-584. [CrossRef]

35. SAS Institute. The SAS System for Windows. Release 9.4; SAS Institute: Cary, NC, USA, 2015.

36. Bolaños, J.; Edmeades, G.O. Eight cycles of selection for drought tolerance in lowland tropical maize. II. Responses in reproductive behavior. Field Crops Res. 1993, 31, 253-268. [CrossRef]

37. Edmeades, G.O; Bolaños, J.; Chapman, S.C. Value of Secondary Traits in Selecting for Drought Tolerance in Tropical Maize; Edmeades, G.O., Ed.; Developing drought and low-N tolerant maize; CIMMYT: Mexico, Mexico, 1997; pp. $222-234$.

38. Herrero, M.P.; Johnson, R.R. Drought stress and its effects on maize reproductive systems. Crop. Sci. 1981, 21, 105-110. [CrossRef]

39. Ribaut, J.M.; Betran, J.; Monneveux, P.; Setter, T. Drought tolerance in maize. In Handbook of Maize: Its Biology; Bennetzen, J.L., Hake, S.C., Eds.; Springer: New York, NY, USA, 2009; pp. 311-344.

40. Ordás, B.; Revilla, P.; Malvar, R.A.; Butrón, A.; Ordás, A. Eighteen cycles of recurrent mass selection for early flowering in two maize synthetics. Euphytica 2019, 215, 49. [CrossRef]

41. Samayoa, L.F.; Butrón, A.; Revilla, P.; Alvarez, A.; Malvar, R.A. Five cycles of mass selection for earliness and ear appearance under corn borer infestation in the maize synthetic BS17. Crop. Sci. 2012, 52, 2432-2437. [CrossRef]

42. Hawtin, G.; Iwanaga, M.; Hodgkin, T. Genetic resources in breeding for adaptation. Euphytica 1996, 92, 255-266. [CrossRef]

43. Ribaut, J.M.; Fracheboud, Y.; Monneveux, P.; Bänziger, M.; Vargas, M.; Jiang, C. Quantitative trait loci for yield and correlated traits under high and low soil nitrogen conditions in tropical maize. Mol. Breed. 2007, 20, 15-29. [CrossRef]

44. Badu-Apraku, B.; Akinwale, R.O.; Franco, J.; Oyekunle, M. Assessment of reliability of secondary traits in selecting for improved grain yield in drought and low-nitrogen environments. Crop. Sci. 2012, 52, 2050-2062. [CrossRef]

45. Chen, Z.; Liu, Y.; Yin, Y.; Liu, Q.; Li, N.; Liu, X.; Li, X.; Guo, C.; Hao, D. Development of dwarfish and yield-effective GM maize through passivation of bioactive gibberellin. Transgenic Res. 2019, 28, 589-599. [CrossRef] [PubMed]

46. Rocheford, T. The Illinois long-term selection experiment, related studies, and perspectives. In Handbook of Maize: Its Biology; Bennetzen, J.L., Hake, S.C., Eds.; Springer: New York, NY, USA, 2009; pp. 483-500. 